\title{
VULNERACIÓN DEL DERECHO DE LA MUJER A DECIDIR SOBRE SU CUERPO, ANTE LA NEGATIVA A EJECUTARLE UN PROCEDIMIENTO DE INTERRUPCIÓN DE EMBARAZO PRODUCTO DE UNA VIOLACIÓN SEXUAL
}

VIRIDIANA CORTÉS TORRES ${ }^{1}$

RESUMEN: Este artículo examina la eficacia de un mecanismo de control constitucional (juicio de amparo), como instrumento protector de los derechos humanos, cuando la naturaleza de la problemática supera los plazos previstos por la ley para resolver. ¿Qué tan eficaz resultan las sentencias del juicio de amparo en dichos casos, los quejosos son realmente reparados o restituidos en sus derechos humanos consagrados en nuestra Constitución o se limitan a ser sentencias con efectos únicamente declarativos?.

Palabras clave: Fuicio de Amparo, Derechos Humanos, Reconocimiento, Protección, Efectos, Procedimiento, Eficacia.

ABstract: This article examines the effectiveness of a constitutional control mechanism (amparo trial), as a protective instrument of human rights, when the nature of the problem exceeds the deadlines set by law to resolve. How effective are the judgments of the amparo trial in such cases, the complainants are really repaired or restored to their human rights enshrined in our Constitution or are limited to being declarative.

Key words: Amparo Trial, Human Rights, Recognition, Protection, Effects, Procedure, Efficacy.

Sumario: I. Introducción; II. Reconocimiento del derecho humano a la libertad reproductiva a nivel Internacional; III. Instrumentos Jurídicos Internacionales; IV. Reconocimiento de los derechos sexuales y reproductivos en México; V. Regulación del Aborto en México; VI. Caso Marisol P. A. en el Estado de Morelos; VII. Resoluciones de la Suprema Corte de Justicia de la Nación sobre la despenalización del aborto en el Distrito Federal, ahora

1 Licenciada en Derecho (UNAM), Especialista en Derecho Constitucional y Amparo, (UNAM), Directora de Concentración y Concesiones del Instituto Federal de Telecomunicaciones. Funcionaria del Poder Judicial Federal del Decimoctavo Circuito. 
Ciudad de México; VIII. Aportación; IX. Fuentes de Consulta.

\section{INTRODUCCIÓN}

n la actualidad México ha avanzado en el reconocimiento de los derechos humanos de la mujer, en general se ha adoptado una teoría progresista a fin de crear mecanismos y políticas públicas dirigidas al reconocimiento, difusión, protección y salvaguardar de los derechos humanos. Se pensaría que las mujeres a pesar de representar en el censo nacional, ${ }^{2}$ un porcentaje mayor de la población en el país no deberían ser consideradas un grupo vulnerable, sino al contrario sus derechos humanos y el reconocimiento de estos deberían ser de accesibilidad inmediata.

Sin embargo, en la actualidad dicha evolución al reconocimiento del derecho humano de la mujer consistente en la reproductivo, también reconocido como la libertad reproductiva, pareciera sólo la documentación de dichos derechos que no son aplicables a realidades concretas. Las mujeres siguen siendo un punto vulnerable e individuo frecuente del sometimiento a sus derechos humanos, es del conocimiento que existe normatividad internacional y nacional que reconoce los derechos de las mujeres, pero a pesar de ello, pareciera que hasta los mismos entes dotados de facultades para reconocerlos y salvaguardarlos, al momento de ejercer su potestad no justifican su actuar, ni motivan sus decisiones, dejándolo en un factor meramente subjetivo que atiende a ideas personales y morales del individuo.

2 Dato extraído de la página oficial Instituto Nacional de Estadística y Geografía, consultada veinte de mayo de dos mil dieciocho, en: <www.inegi.org.mx> Encuesta intercensal 2015, realizado 6.1 millones de viviendas, permitiendo obtener la información a nivel nacional, entidad federativa y municipio. 
II. Reconocimiento del DeRecho humano a La libertad REPRODUCTIVA A NIVEL INTERNACIONAL

Los derechos reproductivos, expresamente no están reconocidos como tales en algún tratado internacional, ni en alguna declaración universal de derechos, mucho menos a nivel regional; sin embargo, se estima que al estar directamente vinculados e íntimamente relacionados con otros derechos sí contemplados en marcos jurídicos internacionales y nacionales, de ahí que puede afirmarse que sí existe su reconocimiento, en ambos marcos jurídicos.

Regina Tamés en la presentación de su obra "Libertad Reproducti$v a$ " señala como primer acercamiento al reconocimiento de los derechos reproductivos en el ámbito internacional la Proclamación de la Conferencia Internacional de Derechos Humanos de Teherán de 1968, en donde se reconoce a nivel internacional que los derechos reproductivos son derechos humanos. Lo que nos deja ver que esta oleada que pareciera reflejar el nacimiento de dicho reconocimiento, en realidad no lo es, ya que desde 1968, existe el antecedente de su declaración, por lo que la autora señala que lo único novedoso es la denominación, así como su clasificación como una categoría diferente, más no la titularidad y la obligación del Estado de reconocerlos y garantizarlos. ${ }^{3}$

En la Conferencia Internacional de Derechos Humanos de Teherán (1968) se introdujo por primera vez la definición de derecho reproductivo básico: "los padres tienen el derecho humano fundamental de determinar libremente el número de sus hijos y los intervalos entre los nacimientos" ${ }^{4}$ Posteriormente, en la Conferencia Mundial de Población

3 Fernando Silva García (coord.), Garantismo fudicial, Libertad Reproductiva, México, Porrúa, 2011, p. XIV.

4 Proclamación de Teherán, Conferencia Internacional de Derechos Humanos, párrafo 16, consultada el 19 de mayo de 2018, en: <www.ordenjuridico.gob.mx>. 
de Bucarest (1974) $)^{5}$ hubo un avance en dicha definición, pues se otorgó la titularidad ya no sólo a los padres, sino a las parejas y a los individuos como entes independientes, agregándose el derecho a la información, la educación y los medios necesarios para ejercer este derecho reproductivo básico (Principio f, Plan de Acción Mundial de Población). Lo que se complementó en la Conferencia Internacional de Población de México (1984), ${ }^{6}$ tal contribución trae como consecuencia que el Estado garantice a través de políticas públicas el disponer de servicios de planificación familiar.

Sin embargo no fue a partir de la V Conferencia Internacional sobre la Población y el Desarrollo celebrada en el Cairo en $1994^{7}$ que se acuñó el concepto de derechos reproductivos.

\section{INSTRUMENTOS JURÍDICOS INTERNACIONALES}

El derecho a la libertad de reproducción nace del derecho universal a la vida, de ahí por lo que no existe duda de la necesidad de que se contemple en los instrumentos internacionales la figura del aborto.

A fin de llegar a dicha regulación normativa, es necesario hacer una breve referencia de los instrumentos jurídicos que regulan el derecho a la vida, por ser el derecho que podría considerase vulnerado con la figura del aborto.

5 Conferencia Internacional sobre la población y el desarrollo, organizada por la ONU, en la cual participaron 135 países, entre ellos México, consultada el 19 de mayo de 2018, en: <www.inmujeres.cdmx.gob.mx>.

6 Conferencia Internacional de Población México, 1984, Conferencia en la cual se ratificaron los acuerdos de la Conferencia de Bucarest, consultada el 19 de mayo de 2018, en: <https//repositorio.cepal.org>.

7 Conferencia celebrada en El Cairo, organizada por la ONU con la representación de más de 180 Estados, se aprobó un nuevo Programa de Acción para los siguientes veinte años, en el que se contienen destacados en este texto, fecha de consulta 19 de mayo de 2018, en: <www.un.org/popin/icpd/newslett/94_19/ icpd9419.sp/llead.stx.html>. 
1. Declaración Universal de los Derechos Humanos. Aprobada en París por la Asamblea General de las Naciones Unidas el 10 de diciembre de $1948 .^{8}$ En su artículo 3 señala "Todo individuo tiene el derecho a la vida, a la libertad y a la seguridad de su persona".

2. La Declaración Universal de los Derechos del Hombre, contemplan el respeto al derecho a la vida.

3. Declaración Americana de los Derechos y Deberes del Hombre. Aprobada en la IX Conferencia Internacional Americana, celebrada en la ciudad de Bogotá, Colombia, adoptada el 2 de mayo de $1948 .{ }^{9}$ En su artículo I. "Todo ser humano tiene derecho a la vida, a la libertad y a la integridad de su persona". Asimismo, dicho instrumento también regula el derecho a la maternidad en su diverso VII que: "Toda mujer en estado de gravidez o en época de lactancia, así como todo niño, tienen derecho a protección, cuidados y ayuda especiales." es decir ya no se limita al derecho a la vida, sino amplía su margen de cobertura a la atribución de la mujer de poder dar vida.

4. Pacto Internacional de Derechos Civiles y Políticos de 16 de diciembre de 1966, al cual se adhirió México el 24 de marzo de $1981 .{ }^{10}$ En su artículo 6.1. señala "El derecho a la vida es inherente a la persona humana. Este derecho estará protegido por la ley. Nadie podrá ser privado de la vida arbitrariamente".

8 Declaración Universal de los Derechos del Hombre, fecha de consulta 19 de mayo de 2018, en: <http://www.un.org/es/documents/udhr>.

9 Comisión Interamericana de los Derechos Humanos, Declaración Americana de los Derechos y Deberes del Hombre, fecha de consulta 19 de mayo de 2018 , en: <http://www.cidh.oas.org/Basicos/Spanish/Basicos1.htm>.

10 Pacto Internacional de Derechos Civiles y Políticos, fecha de consulta 19 de mayo de 2018, en: <http://www.ordenjuridico.gob.mx/TratInt/Derechos $\% 20$ Humanos/D47.pdf $>$. 
5. Convención Americana sobre Derechos Humanos "Pacto de San José". San José, Costa Rica 7 al 22 de noviembre de 1969. Aprobada en 1980. ${ }^{11}$ En esta Convención los Estados partes se obligan a respetar los derechos y libertades reconocidos en ella y a garantizar su libre y pleno ejercicio a toda persona que esté sujeta a su jurisdicción. Asimismo, en el artículo 4. Señala "Toda persona tiene derecho a que se respete su vida. Este derecho estará protegido por la Ley y, en general a partir del momento de la concepción. Nadie puede ser privado de la vida arbitrariamente".

Como se ha podido advertir son algunos de los instrumentos internacionales a través de los cuales es posible apreciar, como ha evolucionado el derecho a la vida, como nos señaló la autora Regina Tamés, no es que el derecho a la reproducción no estuviera regulado, sí se encontraba inmerso en otro derecho, sin embargo, no había evolucionado el entorno social para que se estimara necesario regular el derecho a la libertad reproductiva y menos aun por lo que se refiere al aborto, como parte de la libertad de la mujeres a poder decidir el tener hijos, sin embargo, uno de los instrumentos que podría estimarse que sobresale es el Pacto de San José, en razón de que este instrumento no únicamente contempla el derecho a la vida, sino que, también prevé que la ley proteja a la vida desde el momento de la concepción.

Las función de dichos instrumentos internacionales, es hacer que los Estados miembros garanticen el reconocimiento, la protección y las libertades que se encuentran contemplados en dichos derechos, además de adoptar las políticas públicas necesarias para su cumplimiento, así como la creación de marco normativo nacional.

11 Departamento de Derecho Internacional, Organización de Estados Americanos, Washington, D.C., Convención Americana sobre Derechos Humanos, (Pacto de San José), fecha de consulta 19 de mayo de 2018, en: <http://www.oas. org/dil/esp/tratados_B->. 
La necesidad de regular la figura del aborto atiende a una carencia social, de ahí que se solicita a los gobiernos en todos los ámbitos de competencia, ya sea internacional, nacional o estatal, a que por medio de sus gobiernos, organizaciones intergubernamentales y no gubernamentales, lleven a cabo las gestiones necesaria a fin de acatar el compromiso con la protección al derecho a la libertad reproductiva de la mujer, así como su derecho a la vida y a la salud, ya que dichos derechos se ven vulnerados al realizarse un aborto no en las condiciones optimas, produciendo en algunos casos la muerte, o padecimientos médicos producto de una mala atención.

Es de destacar que en relación a este punto es donde se tiene que reconocer y garantizar dichos derechos a la mujer por parte del Estado, en gran medida ocupa un papel fundamental los poderes legislativos hablando desde el ámbito federal y estatal, al ser los órganos facultados para determinar, a través de la legislación correspondiente, tomar las medidas necesaria para legalizar el aborto.

El reconocimiento de los derechos reproductivos a nivel internacional y nacional no sólo permite el acceso a la educación sexual, salud, condiciones médicas adecuadas, sino también a la implementación de programas públicos que permitan obtener información y educación en la materia, antes o durante el embarazo, en el parto o posterior a éste, sino también incluye servicios de interrupción del embarazo de forma legal y segura en atención a garantizar el derecho a la libertad reproductiva.

Derivado de las practicas clandestinas del aborto es que surge la necesidad de que el Estado regule mejores condiciones de salud e higiene para llevar a cabo dicho procedimiento medico, a fin de garantizar el derecho reproductivo de la mujer de decidir en tener hijos, en atención a ello es que nace la necesidad de la despenalización del aborto, por lo cual se ha denominado interrupción legal del embarazo o aborto legal "interrupción de un embarazo tras la implantación de un huevo fecundado en el endometrio antes de que el feto haya alcanzado viabilidad (antes de las veintidós semanas de 
edad gestacional con peso fetal de 500 gr. y longitud céfalo nalgas de $25 \mathrm{~cm}) " .{ }^{12}$

\section{Reconocimiento DE LOS DERECHOS SEXuAles Y REPROductivos en México}

Los derechos sexuales y reproductivos se incorporaron a nuestro marco jurídico en el artículo 4 constitucional, ${ }^{13}$ a consecuencia de la reforma de 31 de diciembre de 1974, posteriormente en febrero de 1983, se publicó otra reforma a este mismo precepto a través del cual se añadió el derecho a la protección de la salud. ${ }^{14}$ Dichas adecuaciones al marco jurídico mexicano vinieron a consagrar la obligación del Estado de reconocer los derechos sexuales y reproductivos, no sólo estableció el derecho a la paternidad y la maternidad responsable, sino de proporcionar información y educación necesaria que permita planificar la familiar, a través de la creación de políticas públicas que les sea posible adoptar dichas decisiones de manera libre y voluntaria.

En consecuencia la salud reproductiva se refiere a la capacidad de disfrutar de una vida sexual satisfactoria y sin riesgos, con la libertad de procrear, si lo quiero o no, con quien voy a ejercer tal derecho o no, así como la temporalidad de cuándo y con qué fre-

12 Organización Panamericana de la Salud/Organización Mundial de la Salud, Nicaragua, Derogación del Aborto Terapéutico en Nicaragua, Pág. 10, fecha de consulta 23 de mayo de 2018, en: <htt://www.moviminetoautonomomujeres. org/downloads/38.pdf>.

13 Artículo 4.- [...] Toda persona tienen derecho a la protección de la salud. La ley definirá las bases y modalidades para el acceso a los servicios de salud y establecerá la concurrencia de la Federación y las entidades federativas en materia de salubridad general, conforme a lo que dispone la fracción XVI del artículo 73 constitucional.

14 Leticia Bonifaz Alfonzo, La evolución de los derechos de las mujeres a partir de la Constitución de 1917, México, Suprema Corte de Justicia de la Nación, 2017, p. 86. 
cuencia. ${ }^{15}$ La relevancia del reconocimiento y protección de dichos derechos atiende a nivel nacional e internacional se advierte un déficit contra los derechos de las mujeres, ya que, en muchas ocasiones, se traduce en estar viva o muerta.

\section{v. Regulación del aborto en México}

La práctica del aborto en México es un tema que ha llevado a la sociedad a múltiples debates, desde diversas ópticas de estudio ya sea el médico, ético, sociológico, religioso, jurídico o político, es por ello que en nuestro país no ha sido posible llegar a la unificación de la legalidad del aborto, generando la necesidad de que cada congreso local emita regulaciones especifica en su población.

1. Constitución Política de los Estados Unidos Mexicanos. ${ }^{16}$ Los artículos $4^{\circ}$ y 123 Constitucionales establecen respectivamente: El derecho a decidir el número de hijos y el esparcimiento entre ellos, protección durante el embarazo cuando las mujeres trabajen, así como las condiciones en las que debe trabajar una mujer embarazada, a fin de tener las condiciones de higiene, seguridad y prevención de accidentes de trabajo a fin de garantizar la vida y la salud del producto de la concepción.

2. Código Civil Federal. ${ }^{17}$ Establece en el artículo 22, la protección y el derecho a la vida al señalarse que desde el momento en que un individuo es concebido, entra bajo

15 Martha Patricia Castañeda Salgado (coord.), La interrupción voluntaria del embarazo, Reflexiones teorías, filosóficas y políticas, México, UNAM, Centro de Investigaciones Interdisciplinarias en Ciencias y Humanidades de la UNAM, 2003, p. 139.

16 Constitución Política de los Estados Unidos Mexicanos, fecha de consulta 19 de mayo de 2018, en: <http://www.diputados.gob.mx/LeyesBiblio/pdf/1.pdf>.

17 Código Givil Federal, fecha de consulta 19 de mayo de 2018, en: <http:// www.diputados.gob.mx/LeyesBiblio/pdf/2.pdf>. 
la protección de la Ley. "Título PRIMero De las Personas Físicas La capacidad jurídica de las personas físicas se adquiere por el nacimiento y se pierde por la muerte; pero desde el momento en que un individuo es concebido, entra bajo la protección de la ley y se le tiene por nacido para los efectos declarados en el presente Código".

3. Código Penal Federal. ${ }^{18} \mathrm{Al}$ tipificarse el aborto como la muerte del producto de la concepción en cualquier momento de la preñez, se inclina hacia la tendencia de la protección del producto desde la concepción, contraponiéndose así al derecho y a la libertad de la mujer a decidir sobre su cuerpo y la maternidad. Sin embargo, cabe señalar que este Código contempla algunas excepciones que son excluyentes de responsabilidad tanto para la mujer como para quien practique el aborto:

Artículo 333 No es punible el aborto causado sólo por imprudencia de la mujer embarazada, o cuando el embarazo sea resultado de una violación. ${ }^{19}$

Artículo 334 No se aplicará sanción: cuando de no provocarse el aborto, la mujer embarazada o el producto corran peligro de muerte, a juicio del médico que la asista, oyendo éste el dictamen de otro médico, siempre que esto fuera posible y no sea peligrosa la demora.

4. Código Federal de Procedimientos Penales. ${ }^{20}$ De este marco jurídico se desprende que cuando está acreditado el delito y la probable responsabilidad del inculpado en materia de aborto y se da el reconocimiento por parte de

18 Código Penal Federal, fecha de consulta 19 de mayo de 2018, en: <http:// www.diputados.gob.mx/LeyesBiblio/pdf/9.pdf>.

19 Código Penal Federal, fecha de consulta 19 de mayo 2018, en: <http:// www.diputados.gob.mx/LeyesBiblio/pdf/7.pdf>.

20 Código Federal de Procedimientos Penales, fecha de consulta 19 de mayo de 2018, en: <http://www.diputados.gob.mx/LeyesBiblio/pdf/7.pdf>. 
los peritos médicos a la madre para dictaminar las causas del aborto, a través de una prueba de inspección.

El artículo 173, señala que en los casos de aborto o de infanticidio, además de las diligencias mencionadas en los artículos 171 y 172, los peritos médicos describirán las lesiones que presente la madre, y dictaminarán sobre la causa del aborto. En uno y otro caso expresarán la edad de la víctima, si nació viable y todo aquello que pueda servir para fijar la naturaleza del delito. Por lo que respecta a delitos sexuales el artículo 231, señala que puede concurrir al reconocimiento que practiquen los médicos el funcionario que conozca del asunto, si lo juzga indispensable.

Para arribar al tema de la punibilidad de las mujeres que se sometan a un aborto, se estima necesario señalar cuáles son los elementos en los que encuadra el actuar de una mujer al realizarse un aborto.

\section{Elementos del tipo penal del aborto}

El autor Virgilio Ruiz Rodríguez, en su obra "El Aborto", señala los elementos que conforman al delito en general, enlistándolos a continuación::

1. El hecho o conducta. Privación de la vida del producto de la concepción comprende el resultado y la relación de causalidad.

2. Tipicidad. Cuando el hecho realizado: muerte del producto de la concepción.

3. Antijuricidad. Siendo típico el hecho realizado: (muerte del producto de la concepción), no está protegido el sujeto por una causa de justificación.

4. Culpabilidad. Especial naturaleza del aborto, la concurrencia del dolo y por supuesto de mala fe en el sujeto 
que lo realice: "Obra dolosamente el que, conociendo los elementos del tipo penal, o previniendo como posible el resultado típico quiere o acepta la realización del hecho descrito por la ley".

5. Punibilidad. En el orden penal, la sanción o pena con que se castiga al abortador depende de qué tipo de aborto se trate. ${ }^{21}$

\section{Clasificación del delito de aborto}

De acuerdo con el citado autor el aborto, puede clasificarse para su estudio desde dos puntos de vista: 1) Médico y 2) Jurídico-Penal, ${ }^{22}$ por lo cual se estima necesaria la siguiente explicación:

1.- Espontáneo. Este tipo de aborto es secundario a las lesiones maternas u ovulares que provocan alteraciones que pueden conducir al defectuoso desarrollo e incluso a la muerte del huevo, en cuyo caso este es expulsado espontáneamente. Su origen puede ser materno o fetal.

En relación a lo primero se encuentran los tumores genitales, sinequias uterinas, alteraciones de orden funcional del útero, diabetes, hipertensiones, traumatismos, etcétera. Y en relación a lo segundo, tenemos las malformaciones ovulares o embrionarias, déficit vitamínico en la alimentación, alteraciones genéticas relacionadas con el sexo, entre otros.

2.- Provocado. Se indica en la enciclopedia citada que este tipo de aborto constituye un acto criminal. Por ello está prohibido por la ley en la mayoría de los países, y no es aceptable desde el punto de vista médico ni moral. Es el primer aspecto, ordinariamente es el que da lugar a complicaciones y problemas a veces graves.

21 Virgilio Ruiz Rodríguez, El Aborto. Aspectos furídicos, Antropológicos y Ético, Universidad Iberoamericana, México, 2002, p.53.

22 Ibidem. pp. 48-52 
El aborto espontáneo plantea el problema de conocer su origen o causa, el provocado plantea el de su evolución con los peligros que acarrea. 3.- Terapéutico. En terminología médica y jurídica de algunos países se denomina aborto terapéutico a aquel que se provoca para evitar riesgos, reales o supuestos, en una mujer cuyo embarazo puede comprometer su salud.

2.) Desde el punto de vista Jurídico-Penal, se distinguen cuatro tipos a saber:

I.- Aborto culposo. Es el causado solo por imprudencia de la mujer. Se funda en la consideración de que cuando la mujer por sus simples negligencias o descuidos, sin intención dolosa, causa su propio aborto, II.- Aborto casual. En este tipo de aborto, se destruye la presunción de intencionalidad y no se obtiene prueba alguna de un estado culposo imprudente, y no es punible por ausencia de elemento moral. 3.- Por estado de necesidad o terapéutico. Esta clase de aborto es admitido prácticamente por todos los ordenamientos jurídicos. 4.- Aborto honoris causa. En la vía media -dice García Ramírez- Entre el aborto genérico, que sanciona con las penas normales severas, que la ley generalmente previene, y del impune, se encuentra el honoris causa, al que algunos autores prefieren denominar sólo "privilegiado".

La Norma Oficial Mexicana NOM-046-SSA2-2005 define al aborto médico: "la terminación del embarazo realizada por personal médico, en los términos y plazos permitidos de acuerdo con la legislación local aplicable y previo cumplimiento de los requisitos específicos establecidos en esta [Norma]. Cabe señalar que este tipo de aborto se practicará cuando se esté frente a la excluyente de responsabilidad por violación."

Posterior al marco jurídico internacional y nacional, es preciso señalar que sólo en algunos estados está regulado el aborto legal, de ahí que se genera la necesidad de que los estados que están alrededor tengan la necedad de que dicha despenalización se valla generalizando en todo el país fue hasta 2007, que se fue consolidan- 
do por la Suprema Corte de Justicia de la Nación, de ahí surge mi interés por poner atención al tema de la despenalización del aborto fuera de una cuestión de género, de ser un tema en disputa para la sociedad que me rodea, mi interés en el tema redunda en cómo la autoridad jurisdiccional atiende estos casos donde la naturaleza del fenómeno natural, puede rebasar el término de veintidós semanas, plazo que con anterioridad señalada que puede omitir la punibilidad de la interrupción del embarazo.

Por ello, centro mi artículo en la necesidad de crear un medio de control constitucional que sea eficaz frente a la ineficacia del Estado de garantizar los derechos humanos como son la vida, libertad reproductiva y salud, al ser la mujer, el individuo a quien se le ven vulnerados sus derechos por su naturaleza de procrear.

En atención a lo anterior, es que resulta preciso analizar dicha necesidad bajo el reflejo de casos concretos y reales que se desarrollan en la vida cotidiana de las mujeres que habitan en México, por ello hago del conocimiento el caso de una menor de edad que fue víctima de abuso sexual en el Estado de Morelos, entidad donde no se ha legalizado el aborto, sin embargo, los tratados internacionales de protección a la mujer y la legislación federal, le permiten promover un juicio de amparo.

\section{vi. Caso Marisol P. A.}

Por denuncia realizada el treinta de noviembre de dos mil quince, la menor (Marisol P.A.) hizo del conocimiento al agente del Ministerio Público Investigador adscrito a la Fiscalía General del Estado de Morelos, que se había cometido en su contra el delito de violación, a lo cual procedió a la apertura de la carpeta de investigación correspondiente. En la declaración de la menor denunciante realizada el ocho de diciembre de la citada anualidad, se hizo del conocimiento a dicha autoridad, que ha consecuencia del citado acto delictivo se encontraba embarazada. 
Mediante valoración médica de nueve de enero de dos mil diecisiete, realizada a la víctima, ordenada por el área de perinatología, se diagnostico que la menor tenía un embarazo de dieciséis semanas de gestación, puntualizando que el producto presentaba hidrocefalia, lo que implicaba un riesgo alto en el embarazo, diagnostico que fue confirmado, por un ultrasonido, señalando que el producto tenía como padecimiento una "hidrocefalia severa".

Con posterioridad a dicho diagnostico la menor y su madre, solicitaron mediante escrito de quince enero de dos mil dieciséis, la interrupción del embarazo lo que ocasionó la intervención del Comité de Bioética "El Comité Hospitalario de Bioética, será responsable del análisis, discusión y apoyo en la toma de decisiones respecto de los problemas o dilemas bióticos que se presenten en la práctica clínica la atención médica, o en la docencia que se imparte en el área de la salud, así como la elaboración de lineamientos y guías éticas institucionales para la atención y docencia médicas", ${ }^{23}$ a fin de sesionar sobre el análisis de dos solicitudes en los cuales se quería someter a un procedimiento de interrupción del embarazo, entre ellas la de la menor víctima, levantándose el acta correspondiente donde se determinó lo siguiente:

[...] analizados los casos clínicos de las pacientes $(\ldots)$ y (...) con embarazos con productos con una alteración morfológica demostrado en los estudios de ultrasonografía de cada una de ellas, se llega a la conclusión de que no se encuentra ninguna justificación médica para la interrupción de los mismos, por tal motivo al no presentar ninguna de las madres alguna patología, se decide su egreso del hospital ya que su estancia dentro del mismo implica su riesgo a la salud de las pacientes $[\ldots]^{24}$

23 Dora García Fernández y Lorena Malpica Hernández (coords.), Temas de Derecho Biomédico, Colección de Derecho y Bioética, t. III: México, Porrúa-Universidad Anáhuac, 2010, pp. 149-150.

24 Sentencia dictada en el juicio de amparo en revisión 601/2017 del índice de la Segunda Sala de la Suprema Corte de Justicia de la Nación de cuatro de abril de dos mil dieciocho, p. 6. 
Las autoridades sanitarias a quienes acuden las mujeres que han sido víctimas de una violación sexual y que ha consecuencia de ello están embarazadas, deberían ser atendidas de forma eficiente e inmediata a solicitud de someterse a la interrupción legal del embarazo, ${ }^{25} \mathrm{a}$ fin de que las consecuencias físicas, psicológicas derivadas de la agresión sexual sigan produciendo efectos en la víctima, ya que tal negativa ocasiona que se vea vulnerado su derecho a la integridad física, a la salud y a la libertad de decidir sobre su cuerpo.

Lo anterior, es algo que se considera debería suceder a fin de preservar la integridad física de la víctima, sin embargo, el cuatro de febrero de dos mil dieciséis, se presentó un escrito de demanda de amparo indirecto ante los Juzgados de Distrito en el Estado de Morelos, donde una menor de diecisiete años, por conducto de sus representantes solicitó la protección de la Justicia de la Unión contra las autoridades del Hospital General de Cuernavaca, señalando como acto reclamado "tratos crueles e inhumanos, equiparables a tortura a que se ha sometido a nuestra hija de 17 años al negarle el servicio médico de interrupción del embarazo producto de una violación sexual además de que al producto se le ha diagnosticado hidrocefalia".

Asunto que por razón de turno correspondió al Juzgado Tercero de Distrito en el Estado de Morelos, quien registro y admitió la demanda de amparo; posteriormente se remitió para el dictado de la sentencia correspondiente al Juzgado Segundo de Distrito del Centro Auxiliar de la Séptima Región, el cual resolvió el juicio de amparo, sobreseyendo por una parte y, por la otra concedió.

25 El Código Penal para el Distrito Federal ahora Ciudad de México, incluye dos conceptos legales en relación al aborto: a) el aborto forzado y b) el aborto definido sólo a partir de la duodécima semana del embarazo. En el primer caso se trata de la interrupción del embarazo en cualquier momento, sin el consentimiento de la mujer. En el segundo, el aborto se define sólo como la interrupción del embarazo a partir de la decimosegunda semana de la gestación. 
Resulta preciso señalar que el juez de Distrito encargado en emitir la resolución determinó sobreseer el juicio de amparo respecto de las autoridades Subdirector Jurídico de Servicios de Salud de Morelos, y Jefe del Servicio Médico de Ginecología y Obstetricia, ambos del Hospital General de Cuernavaca, Morelos "Dr. José G. Parres", ante la negativa de dichas autoridades de la existencia del acto reclamado consistente en: tratos crueles e inhumanos equiparables a tortura que ha sufrido la menor, así como la negativa de ejecutar la interrupción del embarazo producto de una violación sexual, ante la negativa de las autoridades señaladas como responsables y de que la parte quejosa no ofreció pruebas que le permitieran debatir dicha negativa.

Se determinó conceder el amparo a la víctima respecto del acto reclamado atribuido el Secretario Técnico del Comité de Bioética del Hospital General de Cuernavaca, Morelos “Dr. José G. Parres”, pues aun a pesar de negar el acto que se les atribuyó, dicha negativa se vio desvirtuada con el "Acta de Reunión de Trabajo del Comité de Bioética" de fecha veintiocho de enero de dos mil dieciséis, con la cual se concluyó que no existía justificación alguna para interrupción del embarazo, negando el acceso a someterse al procedimiento solicitado por la menor víctima; sin embargo, de tal determinación se concluyó que en razón de que dicha "Acta de Reunión de Trabajo del Comité de Bioética", no contaba con los elementos dogmáticos y jurídicos, que les permitiera arribar a dicha negativa.

Lo anterior, refleja que las instituciones toman sus decisiones no con base en argumentando jurídicos o científicos, sino en ideas conservadoras que impiden que las mujeres cuenten con la posibilidad de acceder a su derecho humano a decidir sobre su cuerpo.

En concreto concedió el amparo en atención a falta de fundamentación y motivación). Resulta preciso cuestionarse qué tan eficaz es que se concede el amparo y protección de la Justicia para el efecto de que la autoridad que emitió el acto de molestia lo funde y motive adecuadamente, cuando como víctima de una violación 
sexual, el paso de los días y semanas, puede ocasionarte un perjuicio irreparable.

Se hace hincapié que ante la no legalización del aborto en el Estado de Morelos, la menor víctima no cuenta con la libertad para poder ejercer su derecho a decidir procrear o no, y es en atención a ello es que las autoridades médicas tenían que someter a consideración de un Comité la ejecución de dicho procedimiento, sin embargo, a pesar de tener el conocimiento que la solicitud de la paciente atendía a un caso de violación sexual y que de los estudios clínicos a los que se vio sometida se acreditaba que el producto presentaba una alteración morfológica grave, se determinó lo siguiente:

[...] después de un análisis del expediente clínico integrado conforme a la Norma Oficial Mexicana, se concluye que se trata de una paciente con un embarazo normoevolutivo, que si bien es portadora de una malformación congénita y la cual no pone en riesgo la vida de la madre. No contamos con sustento ni orden legal para el terminó del mismo. ${ }^{26}$

En el mismo juicio se solicitó la suspensión del acto reclamado (negativa de llevar a cabo el procedimiento de aborto).

En desacuerdo a tal determinación la víctima interpuso recurso de revisión mediante escrito de veinticuatro de junio de dos mil diecisiete, ante la oficina del Juez Tercero de Distrito en el Estado de Morelos, el referido recurso se remitió para su conocimiento al Primer Tribunal Colegiado en Materias Penal y Administrativa el Décimo Octavo Circuito, órgano que en sesión de veintiocho de octubre de dos mil diecisiete, dictó sentencia en la que determinó solicitar se ejerciera su facultad de atracción la Suprema Corte de Justicia de la Nación, a fin de que conociera de la citada problemá-

26 Sentencia dictada en el juicio de amparo en revisión 601/2017 del índice de la Segunda Sala de la Suprema Corte de Justicia de la Nación de cuatro de abril de dos mil dieciocho, p. 6. 
tica, solicitud que fue resuelta en sesión de diecisiete de mayo de dos mil diecisiete.

Vil. Resoluciones de la Suprema Corte de Justicia de la Nación sobre la despenalización del aborto en el Distrito Federal, ahora Ciudad de México

La máxima autoridad jurisdiccional de nuestro país ha emitido pronunciamientos en relación a la despenalización del borto. En 2008, resolvió la acción de inconstitucionalidad 146/2007 y su acumulada $147 / 2007,{ }^{27}$ por la cual declaró valida la reforma por la cual se despenalizó el aborto voluntario dentro de las dos primeras semanas de embarazo y se instruyó a las instituciones de salud pública a prestar los servicios médicos, dicho pronunciamiento atiende a la necesidad de combatir problemas de salud pública, en los cuales se pueden ver vulnerados los derechos humanos a la vida y a la salud, ya que al llevarse acabó el aborto de manera clandestina no se procura, salvaguardar la integridad de las mujeres que se someten a dicho procedimiento, en atención a que acuden con personas que no cuentan con el conocimiento suficiente, así como tampoco se cuenta con las condiciones de higiene y de indumentaria que les permita asegurar su integridad física.

La Suprema Corte de Justicia de la Nación, registró de Marisol P. A., bajo el número de expediente 667/2016 y resuelto por la Segunda Sala del Alto Tribunal Constitucional del país, en el sentido de ejercer la aludida facultad y conocer del recurso de revisión, tomando en consideración los siguientes aspectos:

27 Acción de Inconstitucionalidad 146/2007 y su acumulado 147/2007, Ministro Ponente: Sergio Salvador Angiano, Ministro encargado del engrose: José Ramón Cossío Días, sentencia de 28 de agosto de 2008, Suprema Corte de Justicia de la Nación. 
I. Se precisó que la problemática planteada, no era un hecho aislado, que al contrario era una situación común en el territorio nacional, señalando que prácticamente en todas las legislaciones penales del país se prevén supuestos normativos que permiten la interrupción del embarazo como consecuencia de una violación, o bien, cuando el producto tiene alteraciones congénitas o genéticas.

II. En atención a lo anterior, es que estimó necesario emitir un criterio que sirviera de guía a los operadores jurídicos, y para los profesionales de la salud.

III. Se concluyó que en el citado asunto se analizaría si existía una vulneración en el proyecto de vida de la menor, al no permitírsele la interrupción del embarazo.

IV. Pero el punto, que estimo de mayor relevancia va encaminado a considerar la posibilidad de determinar si en este tipo de casos las autoridades están obligadas a dar celeridad a las investigaciones; con la finalidad de poder interrumpir el embarazo a tiempo y evitar poner en peligro la salud de la menor y afectar su proyecto de vida. ${ }^{28}$

La Suprema Corte de Justicia de la Nación determinó entrar al estudio del fondo del asunto, tomando en consideración los puntos citados con anterioridad, para ello estimó pertinente fijar la Litis del presente asunto "[...] el acto que se reclama por parte de la quejosa, es la negativa a la interrupción legal de embarazo solicitada por Marisol P. A., al derivar del producto de una violación sexual, lo que se tradujo en una violación de derechos humanos". ${ }^{29}$ Por lo anterior, es que el tribunal de alzada determinó que el juez de Distrito estaba obligado a analizar el fondo de las violaciones a los derechos

28 Sentencia dictada en el juicio de amparo en revisión 601/2017 del índice de la Segunda Sala de la Suprema Corte de Justicia de la Nación de cuatro de abril de dos mil dieciocho, pp. 10-11.

29 Ibidem pp. 13-14. 
humanos de la menor víctima y no, sólo pronunciarse sobre posibles violaciones al procedimiento, como sucedió, en específico por referirse a la falta de fundamentación y motivación.

En relatadas consideraciones, es que la Suprema Corte de Justicia de la Nación resolvió que se había violado gravemente los derechos humanos de la menor Marisol P. A., de manera directa y a sus padres de manera indirecta, al no permitírsele practicar aborto respecto de un producto consecuencia de una violación sexual y que, además presentaba una alteración congénita (hidrocefalia severa), al ser ambas razones excluyentes de responsabilidad del delito de aborto, previsto en el artículo 119 del Código Penal para el Estado de Morelos, ${ }^{30}$ ante la negativa del Comité de Bioética de realizarle el procedimiento de interrupción del embarazo, se tradujo en una violación grave a los derechos sexuales y reproductivos de la menor quejosa Marisol P.A. ${ }^{31}$

Criterio reiterado emitió la Corte en un amparo promovido por una mujer a la cual se le negó la atención médica para interrumpir su embarazo producto de una violación en contra del Hospital General "Dr. Aurelio Valdivieso" del Estado de Oaxaca, señalando que las autoridades de salud deben contar con políticas de salubridad para atender este tipo de casos de manera urgente, ello en atención a tener el deber de garantizar, sin dilación alguna, los de-

30 Artículo 119.- No es punible el aborto:

I.- Cuando sea resultado de una acción notoriamente culposa de la mujer embarazada;

II.- Cuando el embarazo sea resultado de un delito de violación;

III.- Cuando de no provocarse el aborto, la mujer embarazada corra peligro de muerte, a juicio del médico que la asista, oyendo éste último el dictamen de otro médico, siempre que ello fuere posible y no sea peligrosa la demora;

IV.- Cuando a juicio de un médico especialista se diagnostiquen alteraciones congénitas o genéticas del producto de la concepción que den como resultado daños físicos o mentales graves, siempre que la mujer embarazada lo consienta; y

V.- Cuando el embarazo sea resultado de la inseminación artificial realizada sin el consentimiento de la mujer.

31 op cit.p. 16. 
rechos que tiene una mujer como víctima de una violación sexual, lo que implica dotar de cierta clasificación a este tipo de asuntos como de urgencia, en atención a evitar que las consecuencias físicas y psicológicas se sigan desplegando en el transcurso del tiempo. ${ }^{32}$

De los citados casos es posible apreciar la necesidad de crear los mecanismos adecuados y eficientes, a fin de salvaguardar los derechos humanos a la libertad sexual y reproductiva de las mujeres, entendidos como el derecho de las personal a tener control respecto del ejercicio de su sexualidad, a decidir de manera libre, responsable e informada del número y esparcimiento de sus hijos, dichos derechos no atiende a género, edad, orientación social o alguna otra característica, ya que son derechos fundamentales universalmente reconocidos con naturaleza de derechos humanos, ${ }^{33}$

Ante las deficiencias no propiamente del juicio de amparo, si no, atendiendo a la que se ve rebasado por la naturaleza del hombre (transcurso de las semanas del embarazo), se ve reducida su eficacia ante la concesión de un amparo, ya que como se analizó en el caso de Marisol P.A., el máximo órgano jurisdiccional le concedió el amparo de la Justicia de la Unión, aunque los efectos causaron un precedente jurídico para las autoridades, para la víctima se trasgredieron sus derechos humanos de manera irreparablemente.

\section{Vili. Aportacionones}

En razón de lo anterior, es que propongo un procedimiento súper sumario cuando la naturaleza de la problemática no permita que la autoridad resuelva en los plazos contemplados por la ley, no atendido como desacato al mandato normativo, sino atendiendo a la naturaleza del fenómeno social que se someterá a su jurisdicción.

32 Suprema Corte de Justicia de la Nación, "Instituciones de salud deben contar con políticas de salubridad para atender casos urgentes de interrupción legal del embarazo", Compromiso, México, Año 16, № 202, Abril de 2018, p.41.

зз op cit. pp. 84-85. 
En los casos citados en el presente artículos, a los cuales el Máximo tribunal del país tuvo que emitir pronunciamiento ante la necesidad de la sociedad de salvaguardar derechos humanos de la víctimas, con el objetivo de auxiliara a los operadores jurídicos a resolver desde el momento en que el asunto recaiga en su persona, de ahí que propongo que desde que el asunto es presentado en la oficialía de partes del órgano jurisdiccional, se le de un tratamiento especial, que le permita tener un plazo breve para su integración, con el objetivo de que sea en poco tiempo que el secretario proyectista lo tenga y pueda dictar la sentencia correspondiente.

Lo anterior, con la finalidad de que el juicio de amparo sea un medio de control constitucional que se adecua a las necesidades que la sociedad va requiriendo, además de cumplir con su objetivo de salvaguardas las disposiciones contenidas en nuestra Constitución.

\section{Fuentes de consulta}

\section{Bibliografía}

Bonifaz Alfonzo, Leticia, La evolución de los derechos de las mujeres a partir de la Constitución de 1917, México, Suprema Corte de Justicia de la Nación, 2017.

Castañeda Salgado, Martha Patricia (coord.), La interrupción voluntaria del embarazo, Reflexiones teorías, filosóficas y políticas, México, UNAM, Centro de Investigaciones Interdisciplinarias en Ciencias y Humanidades de la UNAM, 2003.

García, Dora y Malpica Lorena (coords.), Temas de Derecho Biomédico, Colección de Derecho y Bioética t. III: Colección de Derecho y Bioética, México, Porrúa-Universidad Anáhuac, 2010.

Ruiz Rodríguez, Virgilio, El Aborto. Aspectos Jurídicos, Antropológicos y Ético, Universidad Iberoamericana, México, 2002. 
Silva García, Fernando (coord.), Garantismo Judicial, Libertad Reproductiva, México, Porrúa, 2011.

\section{Sentencias}

Sentencia emitida en el juicio de amparo en revisión 601/2017 del índice de la Segunda Sala de la Suprema Corte de Justicia de la Nación de cuatro de abril de dos mil dieciocho.

Acción de Inconstitucionalidad 146/2007 y su acumulado 147/2007, Ministro Ponente: Sergio Salvador Angiano, Ministro encargado del engrose: José Ramón Cossío Días, sentencia de 28 de agosto de 2008, Suprema Corte de Justicia de la Nación.

\section{LEGISLACIÓN}

Código Civil Federal

Código Federal de Procedimientos Penales

Código Penal Federal

Código Penal para el Distrito Federal

Constitución Política de los Estados Unidos Mexicanos

\section{HeMERografía}

Suprema Corte de Justicia de la Nación, "Instituciones de salud deben contar con políticas de salubridad para atender casos urgentes de interrupción legal del embarazo", Compromiso, México, Año 16, $\mathrm{N}^{\circ}$ 202, Abril de 2018.

\section{Fuentes ELECTRÓNICAS}

Conferencia Internacional de Población México, 1984, https//repositorio.cepal.org 
Conferencia celebrada en El Cairo, organizada por la ONU con la representación de más de 180 Estados, se aprobó un nuevo Programa de Acción para los siguientes veinte años, en el que se contienen destacados en este texto, www.un.org/popin/icpd/newslett/94_19/ icpd9419.sp/1lead.stx.html

Conferencia Internacional sobre la población y el desarrollo, organizada por la ONU, en: www.inmujeres.cdmx.gob.mx

Comisión Interamericana de los Derechos Humanos, Declaración Americana de los Derechos y Deberes del Hombre, http://www.cidh.oas. org/Basicos/Spanish/Basicos 1.htm

Convención Americana sobre Derechos Humanos, (Pacto de San José), http://www.oas.org/dil/esp/tratados_B-

Declaración Universal de los Derechos del Hombre, fecha de consulta 19 de mayo de 2018, en: http://www.un.org/es/documents/udhr

Organización Panamericana de la Salud/Organización Mundial de la Salud, Nicaragua, Derogación del Aborto Terapéutico en Nicaragua, htt://www.moviminetoautonomomujeres.org/downloads/38.pdf

Pacto Internacional de Derechos Civiles y Políticos, http://www.ordenjuridico.gob.mx/TratInt/Derechos\%20Humanos/D47.pdf

Página oficial Instituto Nacional de Estadística y Geografía, www.inegi. org.mx.

Proclamación de Teherán, Conferencia Internacional de Derechos $\mathrm{Hu}-$ manos, www.ordenjuridico.gob.mx 